\title{
Biofilms in the ICU
}

\author{
Kendra P. Rumbaugh PhD
}

\section{WHAT ARE BIOFILMS?}

Biofilms are communities of microorganisms that are adherent to a surface and/or each other and are surrounded by a self-secreted, hydrated matrix composed of polysaccharides, proteins, water, and nucleic acid, often referred to as extracellular polymeric substance or EPS (Figure1). ${ }^{1}$ These communities can be homogeneous but are often polymicrobial and may include bacteria and fungi. Biofilms are not a new problem, but the perspectives of the microbiologists studying them are relatively new. Since Robert Koch developed the methodology of pure culture, microorganisms have been removed from their native

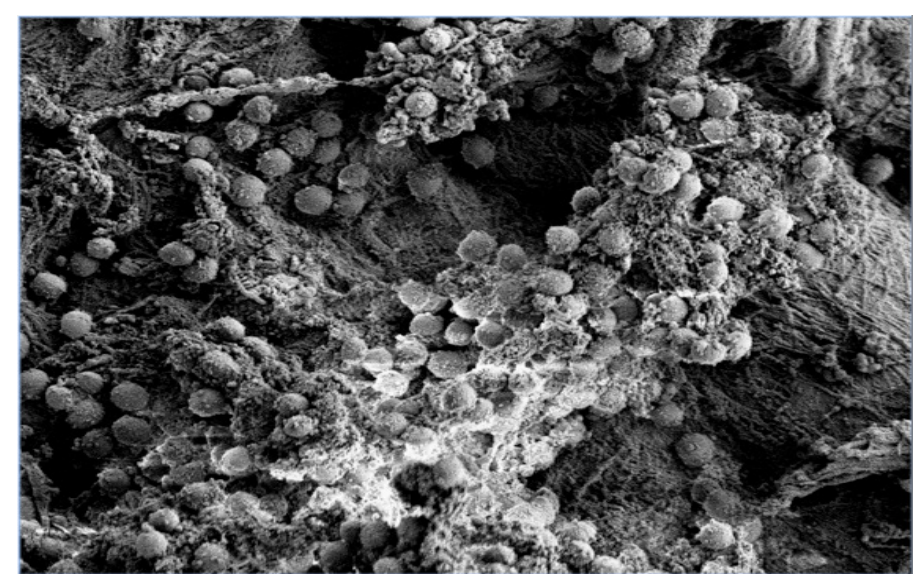

Figure 1. Scanning electron micrograph of a Staphylococcus aureus biofilm growing in an in vitro wound model. Clusters of $S$. aureus cells are coated by a stringy substance which is thought to be EPS. It should be noted that during processing for SEM the EPS becomes dehydrated and flattened. Image at X5, 000 magnification (Rumbaugh laboratory).

Corresponding author: Kendra P. Rumbaugh, PhD Contact Information: kendra.rumbaugh@ ttuhsc.edu

DOI: $10.12746 /$ swrccc2013.0206.067 environments and propagated for study under completely artificial conditions. We now know that these techniques create a selection bias for cells growing in the planktonic, or 'free-living', phenotype, while the biofilm phenotype is the dominant mode of growth for most microorganisms on the planet.

\section{WHY ARE BIOFILMS SO DIFFICULT TO TREAT?}

The differences between bacteria in a biofilm versus the planktonic phenotype are striking. Compared to planktonic cells, biofilm cells have modified doubling times and transcriptional profiles and significantly reduced susceptibility to antimicrobials. Of course, it is this reduced susceptibility to antimicrobials that makes them clinically important. Bacterial cells in biofilms can be up to 1000 times more tolerant to antibiotic agents than free-living planktonic cells. ${ }^{2}$ Biofilm-related antibiotic tolerance is a transient, nonheritable phenotype distinct from conventional mechanisms of antibiotic resistance, which are genetically transferable. Several mechanisms may explain drug tolerance within biofilms. ${ }^{3}$ The two most widely accepted theories are that bacterial cells adopt a sessile or dormant state when living in a biofilm rendering them less susceptible to antibiotics that act only on proliferating cells, and that the EPS surrounding the cells provides a mechanical shield that can inhibit the penetration of antimicrobials.

The classic clinical hallmarks of biofilm infection include the 3Rs- resolution, relapse, and recalcitrance. The chronic cycle of infection begins soon after a biofilm has formed on some surface within the body (Figure 2). As planktonic cells are shed from the biofilm, symptoms of infection are apparent as the immune system mounts a defense. The immune response and antimicrobials effectively kill these planktonic cells, resolving symptoms, and seemingly 
clearing the infection. However, dormant biofilm cells remain, and once the antimicrobial pressure is lifted, symptoms return. This cycle can continue indefinitely through many rounds of antibiotics and is commonly seen in biofilm-related diseases, such as otitis media, tonsillitis, chronic wound infections, urinary tract infections, and sinusitis. ${ }^{4}$ tablish a biofilm. It is estimated that $20 \%$ of ICU patients will get a healthcare-associated infection (HAI), which can result in considerably increased hospital stays, costs, morbidity, and mortality. ${ }^{5}$ The majority of these HAls are biofilm-based and medical devicerelated. It is thought that biofilms allow microbes to persist in the environment despite significant disinfec

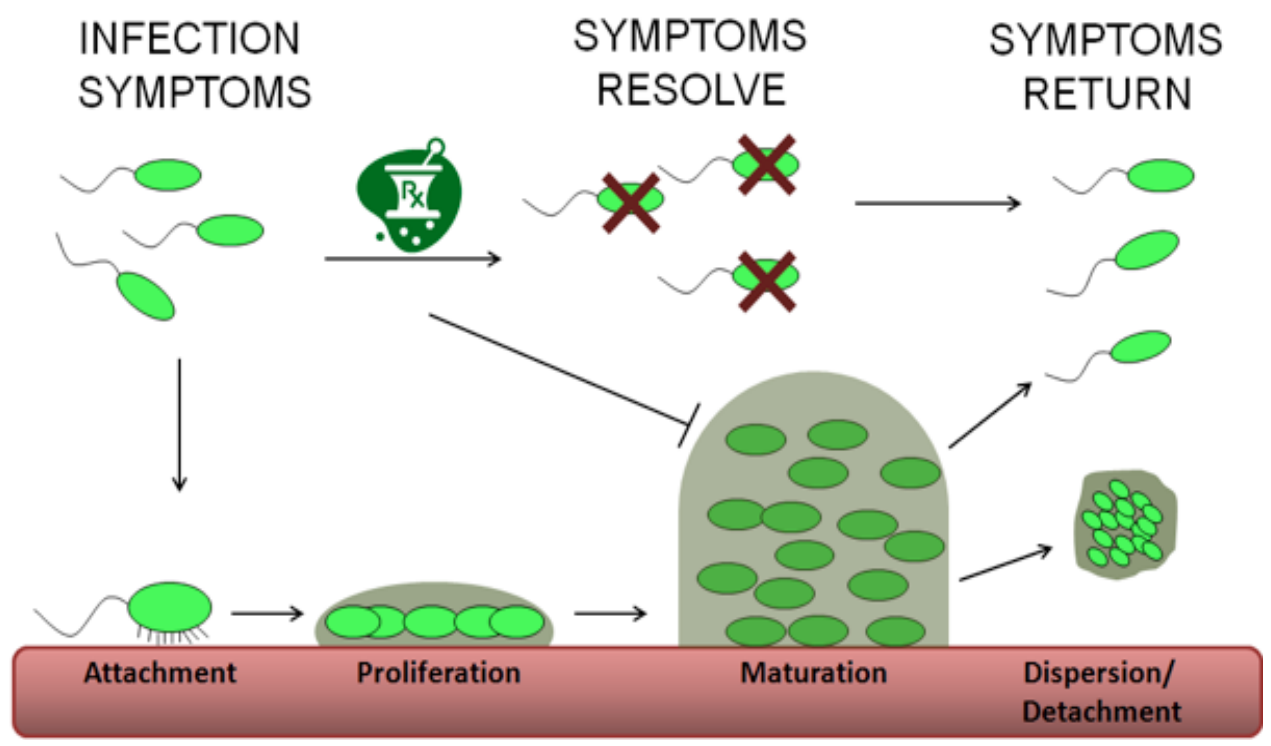

Figure 2. Cycle of biofilm infection. Bacterial cells in planktonic or free-living form enter the body and proliferate, alerting the immune system and resulting in infection symptoms, such as fever and malaise. These cells may also enter the 'biofilm mode of growth' by attaching and proliferating on an abiotic or biotic surface and then differentiating into a mature biofilm community surrounded by EPS. While antibiotic and immune mediators effectively kill planktonic cells, those within biofilms remain viable. Bacterial cells can leave the biofilm community by active dispersion, returning to their planktonic form and reinitiating infection symptoms. Detachment of biofilm cells by mechanical disruption can also result in biofilm growth at other locations.

\section{WHY ARE BIOFILMS PARTICULARLY PROBLEMATIC IN THE ICU?}

Several aspects of intensive care units (ICUs) make them the ideal environment for very dangerous biofilm infections. First, the hospital environment is notoriously associated with microorganisms that cause nosocomial infections, many of which already possess multidrug resistance. Second, ICUs typically house the frailest and most immunocompromised patient populations. And last, the insertion of many types of foreign bodies (e.g. catheters, endotracheal tubes, central lines, etc.) provide an ample variety of surfaces to which microbial cells can adhere and es- tion efforts. A recent study demonstrated that multidrug resistant microbes in biofilms persisted on clinical surfaces in an ICU even after terminal cleaning, indicating that conventional disinfection procedures are not adequate. ${ }^{6}$ Consequently, urinary tract infections, which are the most common HAl, affect over 400,000 patients/yr in U.S. hospitals. ${ }^{7}$ Bloodstream infections related to central venous catheters (CVC) affect 200,000 patients $/ y$ and $30 \%$ of CVC infections in ICU patients are associated with septic shock. ${ }^{8}$

\section{HOW CAN WE DETECT BIOFILMS ON SURFACES?}

Biofilms can form on virtually any environmental surface, but porous or uneven surfaces and those 
with grooves, pits, or other imperfections and/or surfaces that are located in humid areas are more prone to biofilm contamination. Once formed, biofilms can persist in the environment despite stringent cleaning efforts and desiccation and detecting them is a major challenge. ${ }^{6}$ There are no specific tests, stains, or indicators for biofilms; although, researchers are working towards this goal. Furthermore, cells that are in biofilms can become metabolically dormant, making infection control surveillance, which relies on culturability, ineffective. Thus biofilms may be present even when surfaces are 'culture negative'. Contemporary methods for identification of biofilm-contaminated surfaces rely on visualization with electron microscopy and/or detection of microbial nucleic acids, techniques that are not commonly available at most hospitals. ${ }^{6,9}$

\section{WHAT CAN BE DONE TO PREVENT AND/ OR TREAT BIOFILM-RELATED INFECTIONS?}

This question is the subject of intense research in academia as well as in the pharmaceutical industry and was the subject of a recently-published book. ${ }^{10}$ The major strategies being pursued to prevent and/or treat biofilm-related infection are listed in Table 1. Most of these agents are designed to be used in conjunction with conventional antibiotics that kill planktonic cells. Unfortunately, most of these interventions are in the research and development stage and face a long, expensive road to commercialization, filled with many regulatory hurdles. Currently, the most effective treatment option is removal of the biofilm-affected surface. While this is relatively easy to do in device-related infections, biofilms established on human tissue, such as in chronic wounds, often require the amputation of a limb.

In summary, biofilms are a significant problem for hospitals in general and even more so for ICUs. Researchers now have a good understanding about how and where biofilms form, but large gaps in our knowledge remain about prevention, detection and treatment of biofilms. As the medical costs spent on biofilm-related infections and the number of patients they affect continue to rise, scientists hope that funding agencies will make available more support for research in this field.

KeYwords: Biofilm, ICU, hospital-acquired infection, antibiotic tolerance, antibiofilm agents

\begin{tabular}{|l|l|}
\hline \multicolumn{1}{|c|}{ Strategy } & \multicolumn{1}{c|}{ Target(s) and examples } \\
\hline $\begin{array}{l}\text { Degradation or penetration of } \\
\text { EPS }\end{array}$ & $\begin{array}{l}\text { Enzymes that catalyze the hydrolysis of exopolysaccharides or physical } \\
\text { strategies that disrupt the EPS allowing better antibiotic penetration (e.g. } \\
\text { electric current, ultrasound waves, photosensitizers, nanoparticles) }\end{array}$ \\
\hline Quorum sensing inhibitors & $\begin{array}{l}\text { Disrupts the cell-to-cell signaling systems used by some bacteria to facili- } \\
\text { tate biofilm formation (e.g. chemical analogues, antibodies to signals or } \\
\text { signal receptors) }\end{array}$ \\
\hline Bacteriophage & $\begin{array}{l}\text { Highly specific natural bactericidal viruses that are being engineered to } \\
\text { express EPS-degrading enzymes }\end{array}$ \\
\hline Antimicrobial surfaces & $\begin{array}{l}\text { Inhibition of bacterial adherence with various surface coatings (e.g. hydro- } \\
\text { philic polymers and impregnation of antimicrobial agents) }\end{array}$ \\
\hline Dispersing agents & $\begin{array}{l}\text { Agents that promote the dispersion of bacterial cells from the biofilm so } \\
\text { they can be killed in their planktonic form by conventional antibiotics }\end{array}$ \\
\hline
\end{tabular}


Author Affiliation: Kendra P. Rumbaugh is faculty member in the Department of Surgery at TTUHSC.

Received: $2 / 21 / 2014$

Accepted: $4 / 3 / 2014$

Reviewers: Edward Pesanti MD

Published electronically: 4/15/2014

Conflict of Interest Disclosures: None

\section{REFERENCES}

1. Costerton JW, Stewart PS, Greenberg EP. Bacterial biofilms: a common cause of persistent infections. Science 1999;284(5418):1318-22.

2. Mah TF, O'Toole GA. Mechanisms of biofilm resistance to antimicrobial agents. Trends Microbiol 2001 Jan;9(1):349.

3. Donlan RM, Costerton JW. Biofilms: survival mechanisms of clinically relevant microorganisms. Clin Microbiol Rev 2002 Apr;15(2):167-93.

4. Wolcott RD, Rhoads DD, Bennett ME, Wolcott BM, Gogokhia L, Costerton JW, Dowd SE. Chronic wounds and the medical biofilm paradigm. J Wound Care 2010 Feb;19(2):45-6, 8-50, 2-3.

5. Rosenthal VD, Maki DG, Mehta A, Alvarez-Moreno C, Leblebicioglu H, Higuera F, Cuellar LE, Madani N, Mitrev Z, Duenas L, Navoa-Ng JA, Garcell HG, Raka L, Hidalgo RF, Medeiros EA, Kanj SS, Abubakar S, Nercelles P, Pratesi RD. International Nosocomial Infection Control Consortium report, data summary for 2002-2007, issued January 2008. Am J Infect Control 2008 Nov;36(9):627-37.

6. Vickery K, Deva A, Jacombs A, Allan J, Valente P, Gosbell IB. Presence of biofilm containing viable multiresistant organisms despite terminal cleaning on clinical surfaces in an intensive care unit. J Hosp Infect 2012 Jan;80(1):52-5.

7. Klevens RM, Edwards JR, Richards CL, Jr., Horan TC, Gaynes RP, Pollock DA, Cardo DM. Estimating health careassociated infections and deaths in U.S. hospitals, 2002. Public Health Rep 2007 Mar-Apr;122(2):160-6.

8. Francolini I, Donelli G. Prevention and control of biofilmbased medical-device-related infections. FEMS Immunol Med Microbiol 2010 Aug;59(3):227-38.

9. DD, Wolcott RD, Sun Y, Dowd SE. Comparison of culture and molecular identification of bacteria in chronic wounds. Int J Mol Sci 2012;13(3):2535-50.

10. Rumbaugh KP, Ahmad, Iqbal (Eds.). Antibiofilm Agents: from diagnosis to treatment and prevention. Shirtliff M, Stoodley, P., Bjarnsholt, T., editor. New York: Springer; 2014. 